\title{
Perempuan Banjar: \\ Kajian Awal Tentang Sejarah Gender Abad XVIII - XX \\ Mursalin
}

UIN Antasari, Jl A. Yani, Km. 4,5, Banjarmasin, Indonesia

mursalin@uin-antasari.ac.id

\begin{tabular}{ccc}
\hline Received & Accepted & Published \\
$11 / 06 / 2020$ & $02 / 07 / 2020$ & $31 / 07 / 2020$ \\
\hline
\end{tabular}

\begin{abstract}
So far, the concept of gender in Banjarese women is still unclear and ambiguous. This is caused by the absence of research on the concept of gender in Banjarese culture historically. This study aims to understand the social conditions of the Banjar society who form the concept of gender in the XVIII-XX century and describe the gender concept of Banjarese women chronologically in the $X V I I I-X X$ century. This research uses the historical method; heuristics, criticism, interpretation, and historiography. The research presented in this article found that social facts in Banjar society always change depending on the political and economic conditions that occur. Even so, the concept of gender in Banjarese women seems not to change. Women are given wide space and opportunities to play a role in the public-productive sector, of course by not forgetting the task of women in the household as mothers and wives. This shows that social change cannot change the concept of gender in Banjarese women
\end{abstract}

Keywords: Gender, Women, Banjar

\begin{abstract}
Abstrak Selama ini konsep gender perempuan Banjar masih kabur. Hal ini disebabkan oleh tidak adanya penelitian tentang konsep gender dalam budaya Banjar secara historis. Penelitian ini bertujuan untuk memahami kondisi sosial masyarakat Banjar yang membentuk konsep gender abad XVIII-XX dan mendiskripsikan konsep gender perempuan Banjar secara kronologis dalam kurun abad XVIII-XX pula. Penelitian ini menggunakan metode sejarah; heuristik, kritik, interpretasi dan historiografi. Penelitian ini menemukan fakta sosial dalam masyarakat Banjar senantiasa selalu berubah tergantung pada kondisi politik dan ekonomi yang terjadi. Walau demikian, konsep gender perempuan Banjar seakan tidak berubah. Perempuan diberi ruang dan peluang yang luas untuk berperan dalam sektor publik-produktif, tentu dengan tidak melupakan tugas keperempuanannya di rumah tangga sebagai ibu dan isteri. Hal ini menunjukkan bahwa perubahan sosial tidak dapat mengubah konsep gender perempuan Banjar.
\end{abstract}

Kata kunci: Gender, Perempuan, Banjar 


\section{PENDAHULUAN}

Proses interaksi sosial antar manusia menghasilkan pembagian kerja yang memberdayakan semua individu secara berkelompok. Pembagian kerja dibagi berdasarkan kemampuan individu, contohnya perbedaan fisik dan tingkat pengetahuan. Seperti halnya tentang jenis kelamin. Secara fisik serta kemampuan keduanya tentu berbeda. Akibatnya terjadi pembagian peran yang disebut dengan gender. Peran yang identik dengan laki-laki disebut maskulin sedangkan perempuan disebut feminin. Peran maskulin identik berkutat di sektor publik yang produktif, sedangkan feminin berkutat di sektor domestik yang reproduktif. Tentu saja peran maskulin dan feminin pada setiap masyarakat bebeda. Tergantung oleh aspek yang rumit, lebih utamanya adalah kondisi sosial dan budaya.

Istilah gender yang digunakan dalam artikel ini merujuk pada teori West \& Zimeerman. Gender dibentuk oleh konstruksi sosial yang dapat dijelaskan melalui 3 konsepsi, yaitu sex (jenis kelamin secara biologis)- kategori sex (kesadaran jenis kelamin yang dibentuk oleh lingkungan sosial) - gender (pembagian peran berdasarkan jenis kelamin) (West \& Zimmerman, 1987:129131). Teori inilah yang dipakai untuk mengetahui pembagian peran dan konsep gender pada perempuan Banjar yaitu dengan menganalisisnya berdasarkan kesadaran jenis kelamin yang dibentuk oleh lingkungan sosial dan membentuk konsep gender dalam sebuah zaman.

Konsep gender yang tertuang dalam dalam peran domestik-reproduktif dan publikproduktif untuk perempuan Banjar bisa dibilang masih kabur. Peran domestik-reproduktif menggambarkan peran pasif perempuan yang tugasnya hanya dirumah; dapur, sumur, kasur. Contohnya dilihat pada kasus Basurung (menawarkan diri) untuk dinikahi oleh Tuan Guru yang dilakukan oleh perempuan Banjar, meskipun mereka menyadari bahwa statusnya adalah istri kedua, ketiga atau keempat (Nadhiroh, 2017:271). Contoh lain boleh jadi bisa dilihat dalam sastra Banjar. Tokoh Palui nampak sangat dominan dibandingkan perempuan yang kebanyakan cenderung diam, tidak mengambil keputusan dan disalah-salahkan, bahkan sering dijadikan bahan pembicaraan kaum laki-laki (Vidiadari, 2017:282). Kedua contoh diatas tentu menyiratkan bahwa konsep gender perempuan Banjar adalah patriarki.

Disisi lain peran publik-produktif perempuan Banjar juga terlihat. Boleh jadi dilihat pada pasar terapung yang mayoritas pedagangnya adalah perempuan. Belum lagi banyaknya jumlah perempuan Banjar yang mempunyai pendidikan tinggi dan mempunyai karir yang bagus dalam sektor publik, misalnya terlihat pada peran Gusti Nursehan Djohansyah dalam kedudukannya di Dewan Banjar era Revolusi Fisik (Wajidi, 2017:113). Setidaknya contoh ini menyiratkan perempuan Banjar memiliki kesempatan yang sama dengan laki-laki atau bilateral.

Nilai kebaruan dalam penelitian yang dituangkan dalam artikel ini adalah sebuah genre historiografi baru, yaitu sejarah gender. Karena sebelumnya historiografi Banjar tentang perempuan hanya memuat perempuan dan aktifitasnya dalam sebuah peristiwa yaitu skripsi 
Elva Elvandari tentang perjuangan perempuan era Revolusi Fisik, skripsi Syarifah Nazimah dan buku Badruddin tentang perjuangan Ratu Zaleha. Selain itu peneltian tentang gender perempuan banjar dilakukuan oleh Syaifuddin dkk tentang Fatimah binti Abdul Wahab, Gusti Muzainah tentang harta warisan untuk perempuan dan Nuril Huda tentang adat hantaran pada pengantin Banjar. Kesemua penelitian ini tidak merumuskan konsep gender secara utuh, sehingga kadang tumpang tindih. Oleh karena itu, menghindari ketumpang-tindihan ini, maka konsep gender perlu dijabarkan secara diakronik.

Tujuan dari artikel ini pertama, mendiskripsikan kondisi sosial masyarakat Banjar yang mempengaruhi pembagian peran laki-laki dan perempuan abad XVIII-XX. Kedua, merumuskan konsep gender perempuan Banjar abad XVIII-XX.

Batasan spasial dari artikel ini adalah wilayah ini termasuk dalam Kesultanan Banjar,bagian Karesidenan Borneo bagian Selatan dan Timur atau Zuider-en Ooster Afdeeling van Borneo yaitu Afdeling Bandjarmasin dan Afdeling Hoeloe Soengei, Minami Borneo, provinsi Kalimantan serta Kalimantan Selatan pada era sekarang. Sedangkan batasan temporalnya diawali tahun 1734 yang ditandai dengan wafatnya Sultan Kuning dan dimulainya intervensi Belanda terhadap urusan Kerajaan Banjar dan diakhiri tahun 1950 yang ditandai dengan berakhirnya kekuasaan Belanda diboncengi NICA di daerah Kalimantan.

\section{METODE}

Artikel ini diteliti dengan menggunakan metode sejarah; heuristik, kritik, interpretasi dan historiografi. Data primer dikumpulkan berasal dari penelusuran arsip di ANRI Perpusnas RI. Sedangkan data sekunder diperoleh dari buku, monograf dan jurnal yang tersebar di Perpusnas RI, Perpustakaan Pendidikan Sejarah FKIP ULM, dan Perpustakaan Museum Lambung Mangkurat. Bahan yang terkumpul kemudian dipilah untuk mendapatkan data yang valid dan asli. Setelah itu seluruh data ditafsir atau dihubungkan agar membentuk sebuah rangkaian fakta kronologis. Tahap terakhir yaitu ditulis dengan corak penulisan ilmiah yang ilustratif.

\section{HASIL DAN PEMBAHASAN}

Masa Kerajaan Banjar berdiri dikenal tingkatan pelapisan sosial, yaitu Golongan Bangsawan/Tutus Bubuhan Raja, 2) Golongan Orang Besar (pejabat dan pedagang) 3) Golongan Agama (para ulama dan haji) 4) Jaba (masyarakat biasa) dan 5) Pandeling (Ven, 1860:166-167). Bahkan, dalam struktur birokrasi kerajaan, juga terdapat pembagian antara urusan hukum sekuler dan hukum Islam (Azmi, 2017). Walau adanya pembagian demikian, pelapisan ini nampaknya tidak ketat dan seringkali tumpang tindih (Jahmin, 1986:51) yang tidak terlepas dari pengaruh perdagangan lada. 
Golongan bangsawan mengusahakan lada di tanah apanase yang dikerjakan para jaba. Memang hampir seluruh masyarakat kerajaan diwajibkan bekerja untuk golongan ini (Saleh et al., 1977:39). Oleh karena itu golongan tutus raja-raja ini mempunyai peran ganda; sebagai birokrat dan pedagang (Anis, 1994:102).

Setelah kerajaan dihapus, sistem tanah apanase ini juga dihapus. Akibatnya golongan tutus raja-raja kehilangan hak istimewanya dan rakyat terbebas dari kewajiban mengerjakan tanah apanase dan aturan tradisi keraton (Saleh et al., 1977:55). Kekayaan tutus raja-raja digantikan oleh para pedagang yang usahanya berkembang. Selain itu elit ini digantikan oleh pamong praja Belanda (Saleh et al., 1977:55).

Masyarakat Banjar dari lapisan atas sampai ke bawah diatur dalam kelompok kekerabatan besar yang disebut bubuhan yang merupakan kesatuan kelompok darah dan bersifat bilateral, kesatuan ekonomis, kesatuan gotong royong, kesatuan tindakan dalam mempertahankan diri terhadap musuh dan sebagainya (Saleh et al., 1977:40). Pemilihan pimpinan bubuhan berdasarkan usia yang tua, ilmu dan karisma (Saleh et al., 1977:40). Tugas dari kepala bubuhan ini adalah menyelesaikan persoalan internal dan bertanggung jawab pada urusan luar bubuhan (Saleh et al., 1977:40).

Golongan ulama dan haji tetap menjadi spesial dan menjadi elit dalam satu bubuhan. Mereka dipandang sebagai orang yang mampu mengatasi persoalan hidup, memimpin acara keagamaan, serta menjadi pemimpin bubuhan yang lain. Selain itu terdapat juga para dukun, tukang tamba, pawang buaya dan bidan beranak yang mempunyai pengetahuan magis (Saleh et al., 1977:40).

Posisi perempuan pada masa Kerajaan Banjar seringkali dijadikan alat politik, selir atau isteri poligami. Karena kekuasaan, wibawa dan mempunyai pertalian darah dengan raja yang mempunyai kesaktian, golongan tutus raja-raja teramat besar pengaruhnya terhadap kaum perempuan. Mereka harus mematuhi dan mentaati perintahnya, terutama terkait untuk kawin dengan lawan politik, menjadi selir atau isteri poligami. Sedangkan pada kasus poligami ulama bertujuan untuk menyebar jaringan dakwah Islam melalui keturunannya (Rahmadi, 2010:65).

Walau seringkali perempuan menjadi korban kuasa patriarki golongan tutus raja-raja. Hal itu tidak menghalangi mereka untuk berperan dalam sektor publik. Seperti Nyai Kumala Sari yang dengan berani menorobos pembatasan impor garam oleh Belanda karena sebagai permaisuri Sultan Adam, dia merasa memiliki kuasa untuk melakukan perdagangan garam dengan bebas walaupun berbenturan dengan aturan monopoli garam Belanda (Subiyakto, 2010). Begitu pula dengan tokoh Saranti, Nuramin, Fatimah dalam peristiwa di Muning yang muncul pemimpin pasukan perang khusus perempuan (Sjamsuddin, 2014:97). Mengenai posisi sosial dalam masyarakat, perempuan tidak begitu saja disisihkan. Masa ini pula perempuan juga 
dibolehkan memimpin bubuhan pada tingkatan bawah, asalkan berusia tua dan memiliki ilmu serta karisma (Saleh et al., 1977:40).

Sedangkan di era pagustian muncul tokoh Ratu Zaleha yang memegang tampuk pemerintahan dan muncul sebagai pemimpin perang, hingga ditangkap dan diasingkan ke Buitenzorg (Bogor) (Nazimah, 2015:87).

Mengenai peran perempuan dalam rumah tangga (domestik-reproduktif), nampaknya hal ini adalah sesuatu yang lumrah. Bisa dilihat dari peran Ratu Siti yang mengasuh Pangeran Hidayatullah di Karang Intan, tanah lungguh mereka.(Sjamsuddin, 2014:102) Atau Aluh Ungka yang mengasuh Zainal Abidin sampai besar. Bisa dilihat juga peran Aluh Aminah sebagai isteri dari Zainal Abidin yang mendukung peran suaminya sebagai ibu rumah tangga dan mengurus anak. (Noor et al., 2018:76).

Zaman semakin berubah, begitupun kebijakan politik Belanda yang dipengaruhi oleh politik etis. Pengaruh terbesar adalah sektor pendidikan yang memunculkan kaum intelektual pendorong pergerakan nasional. Golongan intelektual ini kemudian mendirikan organisasi pergerakan. Hak-hak perempuan pada masa ini semakin diperhatikan. Perempuan Banjar pun ikut mendapatkan kesempatan mengenyam pendidikan formal.

Perempuan pada masa ini sudah bisa menjadi guru, walaupun untuk sekolah khusus perempuan (Meisjes Vervolgschool). Selain itu terdapat juga Meisjes Normaalschool yang merupakan sekolah lanjutan bagi guru-guru perempuan di Meisjes Cursuus (Saleh, Jamal, et al., 1977:85). Walau Meisjes Normaalschool terletak di Blitar, tapi banyak perempuan Banjar yang sekolah disini.

Peran pendidikan formal ini juga mengakibatkan kesadaran perempuan untuk berorganisasi. Namun lagi-lagi organisasi perempuan pada masa ini merupakan organisasi cabang yang mendukung peran laki-laki atau organisasi yang mencoba mensosialisasikan tentan peran perempuan dalam sektor domestik-reproduktif. Satu diantaranya adalah Sarekat Islam Dunia Isteri yang merupakan bagian dari Sarekat Islam cabang Banjarmasin (Saleh, Jamal, et al., 1977:79). SI Dunia Isteri merupakan wadah bagi perempuan untuk belajar dan membentuk diri dalam berorganisasi, mengelola sekolah Islam, serta membina kerukunan keluarga dan tugas keperempuanan di rumah tangga (Saleh, Jamal, et al., 1977:79-90).

Perempuan pada masa ini juga berhak ikut berpendapat didepan publik. Seperti yang ditunjukkan oleh Siti Sjahrijat, perempuan dari Rukun Putri Parindra. Dia dengan lantang berpidato pada rapat terbuka Parindra di los gatah Pasar Barabai (Wajidi, 2015:21). Hal yang sama juga ditunjukkan Hajjah Saniah dari Rukun Putri Parindra yang berpidato serta berdebat dengan cakap pada kongres Parindra di Bandung (Wajidi, 2015:21).

Selain itu ada juga yang berkecimpung dalam dunia jurnalistik seperti Siti Aisyah isteri A. A Hamidhan. Dia mengasuh rubrik mingguan yang terbit tiap Sabtu bertajuk Iboe Kalimantan 
(Wajidi, 2017:150). Rubrik ini berisi informasi yang berhubungan dengan keperempuanan; pengetahuan masak-memasak, pengetahuan rumah tangga, dan anjuran-anjuran yang berisi tentang cara menghadapi tantangan era perang pasifik untuk keselamatan rumah tangganya (Wajidi, 2017:150).

Sampai tahun 1942 muncul Jepang sebagai pengganti Belanda. Jepang membawa semangat Hakku I Chiu yang wujudnya adalah niponisasi dalam bidang ideologi, budaya, politik dan ekonomi yang berpengaruh pada aspek kehidupan sosial. Bekas karesidenan Borneo Selatan berubah nama menjadi Minami Borneo (Saleh et al., 1977:127).

Jepang memberikan kesempatan kepada seluruh masyarakat tanpa kecuali dan diskriminasi status sosial untuk mengenyam pendidikan formal, termasuk untuk perempuan. Guru-guru untuk pendidikan ini tidak hanya laki-laki, tetapi banyak diantara mereka adalah perempuan. Pemerintah pendudukan Jepang secara khusus pernah memberikan pelatihan selama 25 hari yang diikuti 60 guru perempuan di Rensei Dodjo (Mansyur et al., 2018:71). Tujuan pelatihan ini adalah memperluas bahasa Jepang, bekerja keras secara kinrohosi dan menyalakan semangat (Mansyur et al., 2018:71).

Nampaknya organisasi keperempuanan semuanya diarahkan untuk kepentingan Jepang. Ada indikasi bahwa organisasi ini dilebur kedalam Fujinkai. Selain itu, seluruh isteri-isteri pamong praja dari seluruh tingkat wajib ikut organisasi perempuan ini (Ohorella et al., 1992:35). Tugas Fujinkai adalah mengakomodir para perempuan untuk latihan baris berbaris, latihan berlindung dari serangan udara, menyiapkan kedaraan tentara dan mengumpulkan intan cukilan (Fatimah, 2010:290).

Gusti Nursehan Djohansyah adalah satu diantara anggota Fujinkai di Minami Borneo. Awalnya dia merupakan anggota Rukun Putri Parindra dan isteri pamong praja (Fatimah, 2010:290). Dia bertugas mencari pekerja paksa dari Jawa untuk bekerja di palang merah, penyelenggaraan dapur umum, dan mengusahakan keperluan pangan untuk perang (Fatimah, 2010:290).

Setelah Jepang tidak lagi berkuasa, Indonesia muncul sebagai negara merdeka.. Daerah Kalimantan bagian Tenggara sendiri masuk sebagai provinsi dari Indonesia dengan nama Kalimantan dengan gubernur Ir. Pangeran H. Mohammad Noor. Tidak lama datanglah tentara sekutu yang membonceng NICA dengan maksud mengambil kembali daerah jajahannya.

Perlawanan demi perlawanan tidak terhindarkan di Kalimantan demi mempertahankan kemerdekaan. Perlawanan ini dilakukan dengan cara diplomasi dan bersenjata.

Persatuan Wanita Indonesia (PERWANI) dalam upaya memperjuangkan kemerdekaan tidak dapat begitu saja bisa dikesampingkan. Organisasi ini berdiri tanggal 17 Desember 1946 dengan ketua Gusti Nursehan Djohansyah dengan fokus berjuang untuk kemerdekaan bangsa dan negara melalui sektor politik, ekonomi, sosial dan kebudayaan (Wajidi, 2017:21). Bentuk 
kongkrit perjuangannya adalah mengkoordinir seluruh organisasi perempuan di Kalimantan untuk berjuang dengan cara diplomasi (Nawawi, 1980:117). Koordinasi ini berhasil melaksanakan kongres perempuan se-Kalimantan yang dipimpin langsung Gusti Nursehan Djohansyah pada tanggal 16-18 Juni 1947 (Nawawi, 1980:117). Hasil dari kongres ini yaitu mendukung tuntutan SKI tentang status Kalimantan sebagai bagian dari RI, mendesak Belanda dan RI untuk gencatan senjata dan menyelesaikan soal tawanan politik serta membentuk badan koordinasi organisasi perempuan Indonesia yang menyuarakan perjuangan kemerdekaan bernama Persatuan Tindakan Wanita Indonesia (PERTIWI) (Wajidi, 2017:113). Berkat peran aktifnya, Gusti Nursehan berhasil menduduki kursi Dewan Banjar pembentuk negara federal Kalimantan sebagai tandingan Negara Republik Indonesia. Meski begitu, Dewan Banjar ini dimanfaatkan republiken untuk perjuangan kemerdekaan Indonesia

Pada masa ini perempuan Banjar mulai bisa berdiri sendiri tanpa ada bayangan laki-laki didepannya. Perempuan menemukan tempatnya dalam sektor publik-produktif. Hal ini dapat dilihat dari peran Ny. Gusti Nursehan Djohansyah yang mampu memimpin perempuan untuk menentukan nasib bangsa. Hingga dia sempat diusulkan untuk menduduki kursi legislatif pada Dewan Banjar.

Pengaruh organisasi-organisasi perjuangan turut mempengaruhi pola pikir perempuan. Ditambah dengan kondisi tekanan NICA yang memaksa perjuangan Rakyat Indonesia harus dilakukan dengan cara apapun tanpa memandang jenis kelamin.

Meskipun kondisinya demikian, persepsi masyarakat Banjar tentang peran perempuan dalam sektor domestik-reproduktif tetap saja masih kelihatan. Misal dalam peperangan perempuan berada dibelakang untuk membantu para pejuang; di dapur umum, sebagai perawat, kurir dan sebagainya. Namun hal ini tidak mengurangi kesan perubahan yang lebih positif berkaitan dengan konsep gender perempuan yang berjalan diakronis dalam ruang dan waktu sejarah Banjar.

Selain itu, perjuangan di garda depan peperangan juga dilakukan perempuan secara perseorangan. Tugas mereka adalah sebagai perawat, mengurus pejuang yang tewas pada peperangan dengan berbagai keperluannya, mengurus anak-anak korban perang, mencari keluarga para pejuang yang tewas, menyediakan perbekalan logistik dan makanan, kurir pengantar surat termasuk bahan makanan/obat-obatan untuk mendukung perjuangan kemerdekaan (Nawawi, 1980:117). Juga ada yang berjuang mengangkat senjata, seperti yang dilakukan oleh Aluh Idut dari Kandangan. Idham Khalid pernah menyaksikan Aluh Idut yang disiksa di penjara Belanda dengan cara disetrum (Mansyur et al., 2019:122).

Seakan tidak berubah, konsep gender perempuan pada masa ini memang masih diberi kesempatan untuk berperan dalam sektor publik-produktif, bahkan peran dan kesempatan sangat terbuka luas jika dibanding pada masa sebelumnya. Namun mereka juga dituntut untuk 
menjadi peran pelengkap laki-laki dan melakukan peran domestik sebagai ibu dan isteri. Berdasarkan kondisi sosial masyarakat diatas, maka konsep gender perempuan Banjar bisa dijelaskan dalam tabel 1.

Tabel I

Konsep Gender Perempuan Banjar XVIII-XIX

\begin{tabular}{|c|c|}
\hline KURUN WAKTU & KONSEP GENDER \\
\hline $\begin{array}{l}1734 \text { - } 1905 \text { (Era Kerajaan } \\
\text { Banjar-Perang Banjar- } \\
\text { Pegustian di Hulu Barito) }\end{array}$ & $\begin{array}{l}\text { Pada masa ini konsep gender perempuan Banjar bersifat longgar walau } \\
\text { berada dalam dominasi kekuasaan laki-laki. Hal ini dikarenakan aturan } \\
\text { budaya yang tidak ketat untuk perempuan, asal tidak melupakan } \\
\text { tugasnya sebagai ibu dan isteri. Jika perempuan dalam golongan tutus } \\
\text { raja-raja diberikan kesempatan untuk melakukan peran publik- } \\
\text { produktif, maka begitu pula dengan masyarakatnya. }\end{array}$ \\
\hline $\begin{array}{ll}1901-1942 & \text { (Era } \\
\text { Kebangkitan Nasional) }\end{array}$ & $\begin{array}{l}\text { Meskipun zaman sudah berganti, tetap perempuan mendapatkan } \\
\text { porsinya dalam sektor publik-produktif. Meskipun begitu, tidak } \\
\text { meninggalkan tugas keperempuanannya sebagai ibu dan isteri. Bahkan } \\
\text { pada masa ini perempuan makin banyak diberi tempat dan kesempatan } \\
\text { dalam ranah publik. }\end{array}$ \\
\hline $\begin{array}{l}\text { 1942-1945 } \\
\text { Pendudukan Jepang) }\end{array}$ & $\begin{array}{l}\text { Nampaknya peran perempuan pada masa kependudukan Jepang ini } \\
\text { mengalami perubahan. Meski perempuan diberi hak yang sama dengan } \\
\text { laki-laki dan diberi kesempatan untuk berperan di sektor publik- } \\
\text { produktif, tekanan Jepang akan kepentingan militernya memaksa } \\
\text { perempuan berperan sebagai pelengkap laki-laki di medan pertempuran. }\end{array}$ \\
\hline $\begin{array}{l}\text { 1945-1950 (Era Revolusi } \\
\text { Fisik) }\end{array}$ & $\begin{array}{l}\text { Setelah pemerintah pendudukan Jepang tidak lagi berkuasa dan masuk } \\
\text { era revolusi fisik, perempuan Banjar lebih banyak mendapatkan porsi } \\
\text { untuk tampil didepan publik, bahkan hak-hak tersebut lebih baik dan } \\
\text { terbuka jika dibandingkan dengan pada masa kebangkitan nasional. } \\
\text { Terutama untuk perlawanan terhadap Belanda melalui diplomasi dan } \\
\text { keorganisasian. }\end{array}$ \\
\hline
\end{tabular}

\section{KESIMPULAN}

Kondisi sosial masyarakat Banjar dari waktu ke waktu semakin berubah mengikuti perkembangan zaman. Hal ini dipengaruhi oleh peristiwa-peristiwa yang terjadi dan mengubah kondisi masyarakat. Namun, kondisi sosial tersebut setidaknya berdampak pada konsep gender perempuan Banjar. Era Kerajaan Banjar dan pagustian sangat nampak sekali memposisikan perempuan sebagai alat perkawinan politik, selir dan isteri poligami. Sepintas memang terlihat ke-patriakis-an, tapi walau begitu perempuan tetap dapat berperan dalam sektor publikproduktif. Kemudian berlanjut pada era pergerakan nasional. Munculnya kaum intelektual dan organisatoris perempuan karena telah mendapatkan pendidikan adalah pertanda bahwa meningkatnya kesempatan perempuan berada dalam sektor publik-produktif, meski lagi-lagi mereka diwajibkan pula berperan domestik sebagai pelengkap laki-laki. Nampaknya pada era pendudukan Jepang, tidak sebebas pada era sebelumnya. Jelas sekali perempuan Banjar diarahkan untuk membantu laki-laki dimedan perang melalui Fujinkai. Seakan keadaan berbalik, pada era revolusi fisik, perempuan mendapatkan tempat yang sangat luas untuk melakukan peran publik-produktifnya, meski demikian tetap tidak mengesampingkan peran domestiknya 
dalam rumah tangga, Dengan demikian, konsep gender Urang Banjar adalah bilateral. Meskipun kuasa laki-laki masih saja jelas terlihat, akan tetapi perempuan diberi tempat dan kesempatan yang luas untuk berperan dalam ranah publik-produktif.

\section{REFERENSI}

Anis, M. Z. A. (1994). Struktur Birokrasi dan Sirkulasi Elite di Kerajaan Banjar Abad XIX. Universitas Gadjah Mada.

Azmi, M. (2017). Islam di Kalimantan Selatan pada Abad Ke-15 sampai Abad Ke-17. Yupa: Historical Studies Journal, 1(1), 38-47.

Fatimah, S. (2010). Fujinkai (Women's Asosiation). In P. Post, W. H. Fredrick, I. Heidebrink, \& S. Sato (Eds.), The Encyclopedia of Indonesia in The Pacific War: In Cooperation with The Netherland Institute for War Documentation. Brill.

Ideham, M. S., Sjarifuddin, Usman, A. G., Anis, M. Z. A., \& Wajidi (Eds.). (2003). Sejarah Banjar. Pemerintah Provinsi Kalimantan Selatan.

Jahmin, J. (1986). Raja, Lada dan Pedagang: Kasus Kota Banjarmasin Medio Abad 17-18. Fakultas Pasca sarjana Universitas Gadjah Mada.

Mansyur, Mursalin, \& Wajidi. (2019). Terima Kasih Untukmu Pahlawan: Biografi 4 Pahlawan Nasional dari Kalimantan Selatan (Wajidi (Ed.)). Arti Bumi Intaran.

Mansyur, Wajidi, Sari, M. P., Hairini, S. M., Syakura, A., \& FazlurRahman. (2018). Sejarah Gerakan Kepemudaan di Kalimantan Selatan (Wajidi (Ed.)). Graha Cendikia.

Nadhiroh, W. (2017). Religious and Gender Issues In the Tradition of Basurung and the Polygamy of Banjar Tuan Guru in South Kalimantan. Al-Albab, 6(2), 263. https://doi.org/10.24260/alalbab.v6i2.674

Nawawi, R. (1980). Sejarah Revolusi Kemerdekaan (1945-1949) Daerah Kalimantan Selatan. Departemen Pendidikan dan Kebudayaan.

Nazimah, S. (2015). Ratu Zaleha 1880-1953: Perjuangan Terakhir Perempuan Banjar. Universitas Lambung Mangkurat.

Noor, Y., Mansyur, \& Sayyidati, R. (2018). Adipati Danoeradja Tumenggung Dipanata. Graha Cendikia.

Ohorella, G. ., Sutjiatningsih, S., \& Ibrahim, M. (1992). Peranan Wanita Indonesia dalam Masa Pergerakan Nasional. Direktorat Sejarah dan Nilai Tradisional Departemen Pendidikan dan Kebudayaan.

Rahmadi. (2010). Jaringan intelektual ulama Banjar abad XIX dan XX. Antasari Press.

Saleh, M. I., Asnawi, A., Koroh, A. A., Yustian, D., \& Syah, Y. (1977). Sejarah Daerah Kalimantan Selatan. Pusat Penelitian Sejarah dan Budaya Departemen Pendidikan dan Kebudayaan.

Saleh, M. I., Jamal, B., Koroh, A. A., \& Yustian, D. (1977). Sejarah Daerah Tematis Zaman Kebangkitan Nasional (1900-1942) di Kalimantan Selatan. Proyek Penelitian dan Pencatatan Kebudayaan Daerah Pusat.

Sjamsuddin, H. (2014). Pegustian \& Temenggung: Akar Sosial, Politik, Etnis, dan Dinasti 
Perlawanan di Kalimantan Selatan dan Kalimantan Tengah 1859-1906 (II). Ombak.

Subiyakto, B. (2010). Saudagar Wanita dan Bisnis Garam. https://subiyakto.wordpress.com/2010/04/30/saudagar-wanita-dan-bisnis-garam/

Ven, V. der. (1860). Aanteekeningen Omtrent het Rijk Bandjarmasin. Lange \& Co.

Vidiadari, I. S. (2017). Relasi Gender dalam Kolom Humor "Si Palui" di Banjarmasin Post (Analisis Wacana Kritis Norman Fairclough pada Kolom Humor Si Palui di Banjarmasin Post). ARISTO, 5(2), 259-290. https://doi.org/10.24269/ARS.V5I2.488

Wajidi. (2015). EKSISTENSI PARTAI INDONESIA RAYA (PARINDRA) DI KALIMANTAN SELATAN, 1935-1942. Patanjala: Jurnal Penelitian Sejarah Dan Budaya, 7(1), 17. https://doi.org/10.30959/patanjala.v7i1.80

Wajidi. (2017). Nasionalisme dan Revolusi Indonesia di Kalimantan Selatan 1900-1950. Universitas Lambung Mangkurat.

West, C., \& Zimmerman, D. H. (1987). Doing Gender. Gender \& Society, 1(2), 125-151. https://doi.org/10.1177/0891243287001002002 